\title{
الرضا الوظيفي وعلاقته بالاستمتاع بالحياة لدى معلمي المرحلة الابتدائية في محافظة البصرة (بحث ميداني)
}

م.د. سنان سعيد جاسم الاسدي

07801453023 : الموبايل

\section{sinansaeed8037@gmail.com: الايميل}

\section{كلية التربية القرنة / جامعة البصرة}

: الملخص

يسعى البحث الحالي إلى التعرف على العلاقة ذات الدلالة الإحصائية بين الرضا الوظيفي والاستمتاع بالحياة لاى الدى الإلي

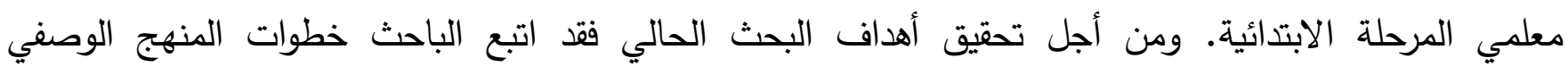

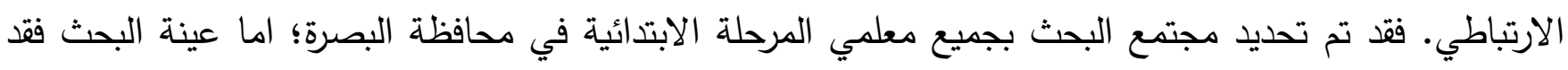
تكونت من (200) معلم ومعلمة.

ومن أجل جمع البيانات والمعلومات فقد قام الباحث بإعداد أدوات البحث الحالي واستخراج الخصائص السايكومترية لها من صدق وثبات.

وبعد الاطمئنان إلى أدوات البحث تم تطبيقها على عينة البحث وتم التوصل إلى مجموعة من النتائج منها : • • هنالك مستوى عالي من الرضا الوظيفي لاى معلمي المرحلة الابتدائية في محافظة البصرة • هنالك مستوى عالي من الاستمتاع بالحياة لاى معلمي المرحلة الابتدائية في محافظة البصرة • هنالك علاقة ذات دلالة احصائية بين الرضا الوظيفي والاستمتاع بالحياة لاى معلمي المرحلة الابتدائية في محافظة البصرة 
مجلة أبحاث ميسان ، المجلد السادس عشر، العدد الثاني والثلاثون ، كانون الأول، السنة 2020

\title{
Job satisfaction and its relationship to enjoying life among primary school teachers in Basra Governorate
}

\author{
Dr. Sinan Saeed Jassim Al-Asadi \\ Mobile: 9401453023 \\ Email: sinansaeed8037@gmail.com \\ Qurna College of Education / University of Basra
}

\begin{abstract}
:
The current research seeks to identify the statistically significant relationship between job satisfaction and enjoyment of life among primary school teachers.
\end{abstract}

In order to achieve the objectives of the current research, the researcher followed the steps of the relational descriptive approach. The research community has been identified for all primary school teachers in Basra Governorate. As for the research sample, it consisted of (200) male and female teachers.

In order to collect data and information, the researcher prepared the current research tools and extracted the psychometric properties of them from the truth and reliability.

After being satisfied with the research tools, they were applied to the research sample, and a set of results were reached, including: 
مجلة أبحاث ميسان ، المجلد السادس عشر، العدد الثاني والثلاثون ، كانون الأول، السنة 2020

1. There is a high level of job satisfaction among primary school teachers in Basra Governorate

2. There is a high level of enjoyment of life among primary school teachers in Basra Governorate

3-There is a statistically significant relationship between job satisfaction and enjoyment of life among primary school teachers in Basra Governorate

\section{الفصل الاول : التعريف بالبحث}

مشكلة البحث

أن مسؤوليات معلم المرحلة الابتدائية عديدة ومتعددة ومتمثلة في جميع مجالات العمل التدريسي ، ويجب أن

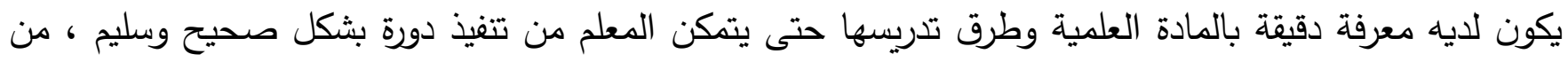
أجل الوصول إلى الرضا عن مهنته التي يعمل فيها ، وهي التدريس ، وان من بين المعلمون من يشعر بالسعادة

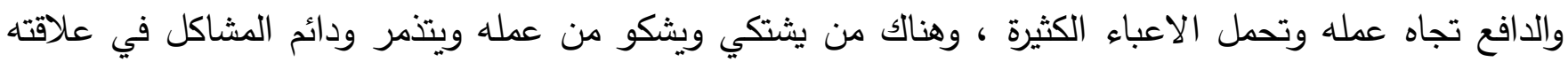

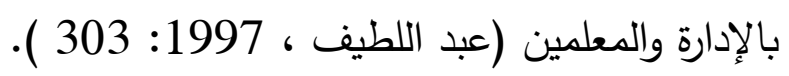

يعتبر الرضا الوظيفي هو الأساس الأول في تحقيق الأمن النفسي والتمتع بالعمل الوظيفي وينعكس إيجاباً على

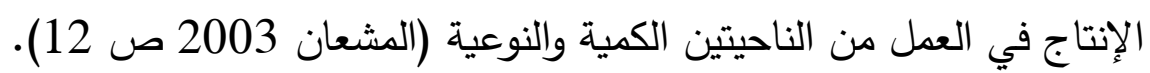

ان أولئك الذين ينخفض رضاهم المهني يعانون من الثعور بالنقص والارتباك وعدم الرضا عن الذات. وقد ينسحبون

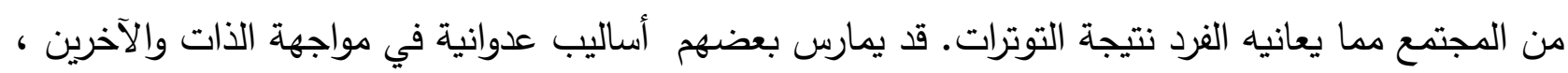

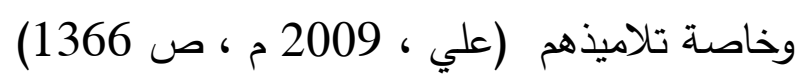

يواجه الناس بشكل عام والمعلمين بثكل خاص في هذا العصر ضغوطات نفسية وصراعات قد تكون مرتبطة

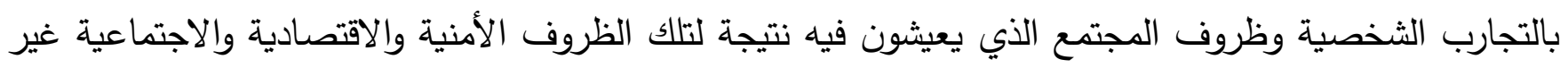

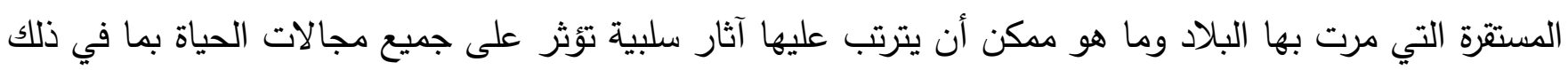


مجلة أبحاث ميسان ، المجلد السادس عشر، العدد الثاني والثلاثون ، كانون الأول، السنة 2020

استمتاعهم بالحياة ، كما أنها تؤثر سلباً على شخصية الأفراد والتلاميذ مما جعلهم يعيشون في قلق دائم

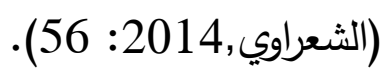

بناءً على ما سبق يمكن تحديد مثكلة البحث بالتساؤلات الآتية : 1.ما مستوى الرضا الوظيفي لاى معلمي المرحلة الابتدائية في محافظة البصرة ؟ 2.ما مستوى الاستمتاع بالحياة لاى معلمي المرحلة الابتدائية في محافظة البصرة .

3.هل هنالك علاقة ذات دلالة احصائية بين الرضا الوظيفي والاستمتاع بالحياة لدى معلمي المرحلة الابتدائية في محافظة البصرة ؟

اهمية البحث

يرتبط الاستمتاع بالحياة بمختف جوانبها الاجتماعية والاقتصادية والسياسية والنفسية ، وعدم الاستقرار في

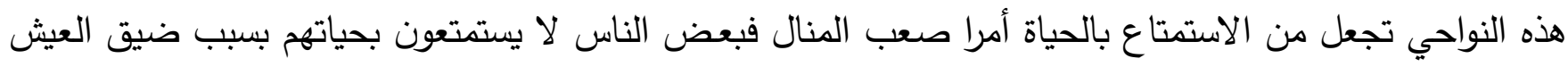

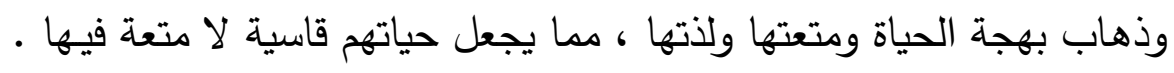

$$
\text { (عبد العال ومظلوم,2013: (80) }
$$

يرتبط الاستمتاع بالحياة بمختلف جوانب الحياة الاجتماعية والاقتصادية والسياسية والنفسية ، وعدم الاستقرار في

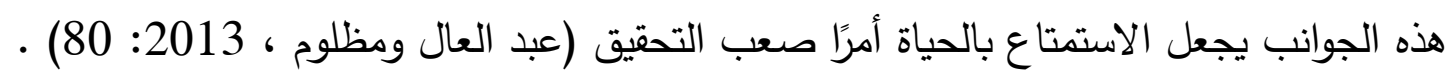
يعتبر الرضا الوظيفي هو الأساس الأول في تحقيق الأمن النفسي والوظيفي للموظفين ، وينعكس إيجاباً على الإنتاج

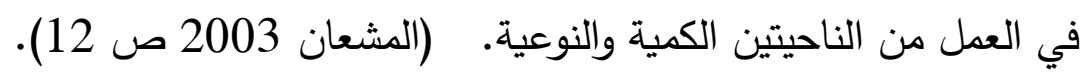
ويمكن تلخيص الاهمية في ما يلي: اولا: الاهمية النظرية

1- تبرز أهمية هذا البحث من طبيعة المتغيرات التي تتاولها وهي (الرضا الوظيفي والاستمتاع بالحياة). حيث أن موضوع البحث الحالي حديث نسبيًا. 
مجلة أبحاث ميسان ، المجلد السادس عشر، العدد الثاني والثلاثون ، كانون الأول، السنة 2020

2- أهمية عينة البحث ممثلة بمعلمي المرحلة الابتدائية في محافظة البصرة ، والدور المهم الذي يلعبونه في

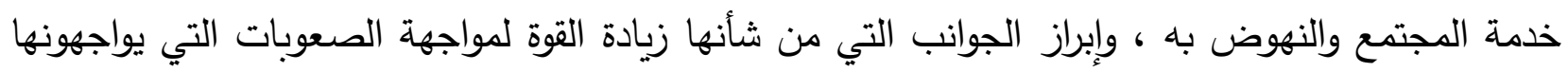
من أجل تحقيق مستوى من المتعة لهم.

3.تقديم إطار نظري لمتغيري البحث (الرضا الوظيفي والاستمتاع بالحياة) وإبرازهما لغرض إثراء المكتبة التربوية والنفسية بثكل عام بالمعلومات النظرية لهذين المتغيرين ، ومله الفراغ وإن كانت جزئية.

4. ندرة الدراسات العراقية والعربية التي تتاولت العلاقة بين الرضا الوظيفي والاستمتاع بالحياة لدى معلمي المرحلة الابتدائية .

أما الأهمية النطبيقية للبحث فتتحدد على النحو التالي: 1- ي يتبر البحث الحالي تغذية مرتدة توفر لمراكز وحدات الإرشاد النفسي في وزارة التربية لتشخيص الأفراد بهذه الخصائص.

2- تتجسد أهمية البحث الحالي في اعداد مقياسي البحث ويمكن الاستفادة منه في إجراء البحوث الأخرى. أهداف البحث يهذف البحث الحالي التعرف إلى : 1. مستوى الرضا الوظيفي للى معلمي المرحلة الابتدائية في محافظة البصرة 2.مستوى الاستمتاع بالحياة لدى معلمي المرحلة الابتدائية في محافظة البصرة . 3.العلاقة ذات دلالة احصائية بين الرضا الوظيفي والاستمتاع بالحياة لدى معلمي المرحلة الابتدائية في محافظة البصرة 
مجلة أبحاث ميسان ، المجلد السادس عشر، العدد الثاني والثلاثون ، كانون الأول، السنة 2020

يتحدد البحث الحالي بالحدود الآتية :

• الحدود البشرية : معلمي المرحلة الابتدائية في محافظة البصرة 0

• • الحدود المكانية : مديرية تربية البصرة

$$
\text { الحدود الزمنية : العام الدراسي } 2019 \text { - 2020 }
$$

\section{تحديد مصطلحات البحث}

job satisfaction اولاً : الرضا الوظيفي

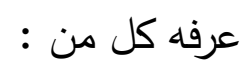

- القيسي 1996

" سلوك يعكس مدى تقبل الفرد الجوانب الوظيفية المتعددة ومدى الثعور بالسعادة " ( القيسي , 1996 م , ص39 )

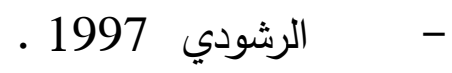

" هو يمثل حصيلة لمجموعة العوامل ذات الصلة بالعمل الوظيفي والتي تقاس اساساً بقبول الفرد لذلك العمل بأرتياح

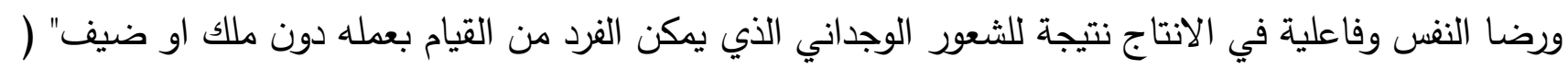

$$
\text { الرشودي , } 1997 \text { م , ص22 موضن ). }
$$

ويتبنى الباحث تعريف (الرشودي,1997) تعريفا نظريا للبحث الحالي •

$$
\text { ويعرف الرضا الوظيفي اجرائياً }
$$

هو شعور ذاتي ايجابي الذي يشعر به المعلم اثناء اداء المهام والواجبات المكلف بها في المدرسة .

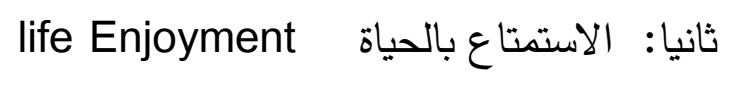


مجلة أبحاث ميسان ، المجلد السادس عشر، العدد الثاني والثلاثون ، كانون الأول، السنة 2020

$$
\text { عرفها كل من : Veenhoven ( }
$$

"درجة تقييم الفرد لجودة حياته الثخصية المعرفية والوجدانية والاجتماعية السلوكية بصفة خاصة من منظور إيجابي واستمتاعه بها ، والذي يعتمد على مدى تتبل الفرد لذاته وللحياة التي يحيها ، ومدى تركيزه على الإيجابيات في حياته أكثر من السلبيات" (1996, Veenhoven: (112)

( (Reade, 2005

"ان يكون الفرد في حالة جيدة من الصحة النفسية والوجدانية والجسمية يعبر عنها الثخص بمشاعر الاستمتاع والبهجة في مختلف مجالاته الحياتية" . Reade , 2005: 720))

((Timothy, 2006

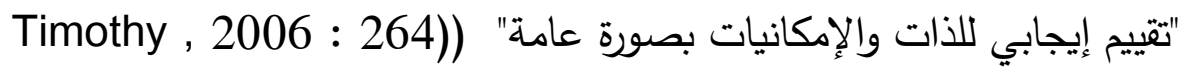
التعريف النظري: تبن الباحث تعريف (Veenhoven,1996) لملائمته لمتطلبات وأهداف البحث الحالي

التعريف الإجرائي : "الدرجة الكلية التي تحصل عليها المستجيب من خلال إجابته على فقرات مقياس الاستمتاع بالحياة خلال مدة زمنية محددة .
\end{abstract}

الفصل الثاني : اطار نظري ودراسات سابقة

اولا: الاطار النظري

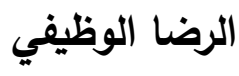

Herzberg,s factors theory tow نظرية الفردريك هزببرج ( 1966 م) 
مجلة أبحاث ميسان ، المجلد السادس عشر، العدد الثاني والثلاثون ، كانون الأول، السنة 2020

تركز هذه النظرية على تحديد العوامل المسببة للرضا او لعدم الرضا الوظيفي , فهو يرى ان هناك عاملان

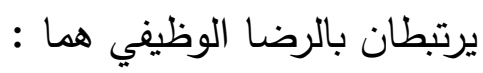

العوامل الداخلية : وتثكل هذه العوامل تلك الجوانب من العمل التي في حال وجودها تشبع حاجات العاملين للنماء النفسي , وهذه غالباً ما تكون واقعة ضمن العمل او كاملة في داخله , والتي في حال توافرها في موقف العمل وبشكل ملائم وايجابي تؤدي بالضرورة الى الثعور بالرضا والثناعة لدى العاملين , ولكن عدم الثم

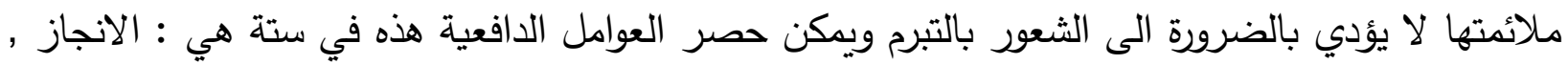

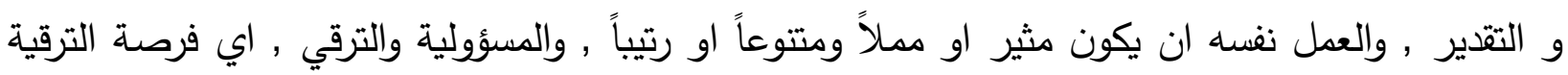

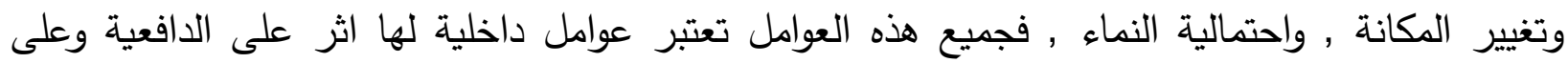
الاحساس بالرضا والقناعة في العمل ,

$$
\text { ( الطويل , } 2001 \text { م , ص55) }
$$

العوامل الخارجية : وهذه العوامل تتعلق ببيئة العمل مثل : سياسية او انظمة المنظمة , والاشراف بين الرؤساء

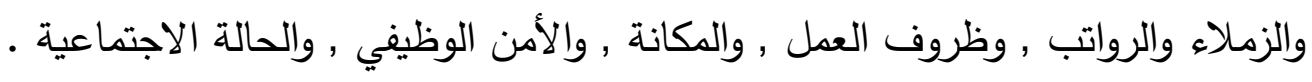

ويرى الطويل ( 2001 م , ص56 ) ان في حالة توافر هذه العوامل او عدم ملائمتها في الوسط الوظيفي فأن تسبب شعور بالقناعة والرضا , ولكن توافرها بشكل عام لا يشكل بالضرورة احساساً او شعور بالرضا والقناعة . ويذكر العديلي ( 1406 هـ , ص205 ) انه وفقاً لهذه النظرية فإن العوامل الدافعية تدفع الفرد وتقوده للعمل , اما

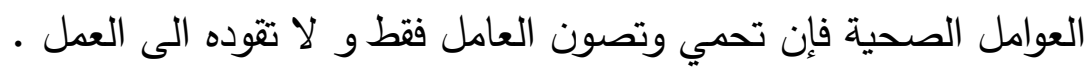

ويرى النمر ( 1413هـ , ص293 ) ان تجاهل الإدارة للعوامل الصحية او الوقائية سيؤدي الى مشكلات تتظيمية و اجتماعية تؤثر على اعمال ونشاطات المنظمة , كما ان هذه العوامل ليست عوامل محفزة بحيث تئدي الى زيادة في

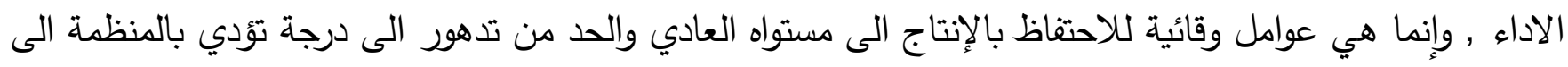

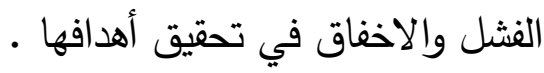

ويشير لاندي وترمبوه trombo \& landy عندما تزداد درجة اشباع العوامل الخارجية يقل الثعور بالاستياء الى دأى النقطة التي يصل فيها هذا الثعور الى درجة الصفر او درجة الحياد التي لا يوجد فيها شعور بالاستياء اما عندما تزداد درجة إثباع العوامل الدافعة فإن الثعور بالرضا يزداد ويصل فيها الثعور الى حالة الرضا العام 


\section{( العديلي , 1403 هـ , ص110 )}

\section{الاستمتاع بالحياة}

Theory of the art of life 1996 نظرية فن الحياة

أكد (فينهوفن ، 1996) ، مؤلف نظرية فن الحياة ، أن المتعة هي القدرة على عيش حياة مُرضية ، وخاصة القدرة

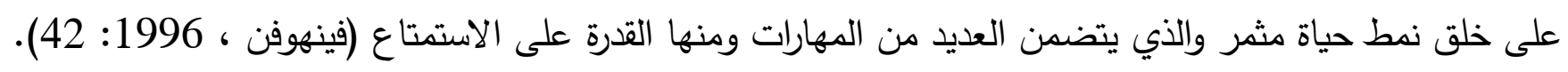
وذكر Veenhoven، 2005 أن الفلسفة النفسية تستلزم أن هدفنا هو تحقيق السعادة النفسية والمتعة لأكبر عدد من الناس (Veenhoven،

والمتعة ذات قيمة عالية في المجتمع في الوقت الحاضر ، فالناس لا يهتمون فقط بالسعادة في حياتهر ، ولكن هنالك

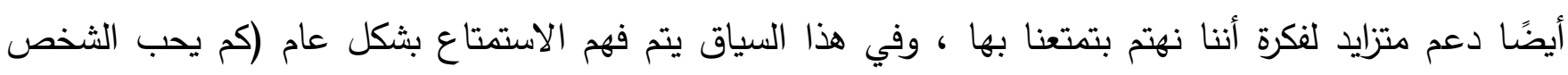

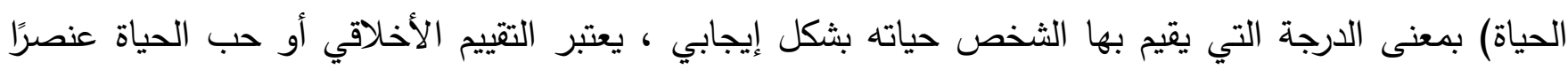
مركزيًا في هذا التعريف ، والذي يتم التعبير عنه من خلا (إرضاء أو إثباع رغبات الحياة) (فينهوفن ، 2005:

\section{مكونات نظرية الاستمتاع بالحياة}

\section{تمثلت نظرية الاستمتاع بالحياة بالمكونات الأساسية:}

1- المكون المعرفي: يشير هذا المكون إلى وعي الفرد بمختلف جوانب حياته بشكل عام ، وإدراكه للرضا عن

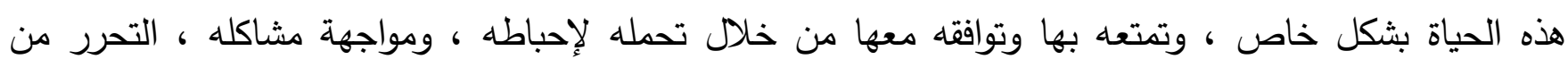

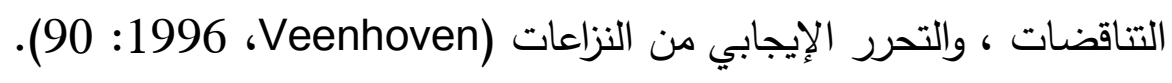

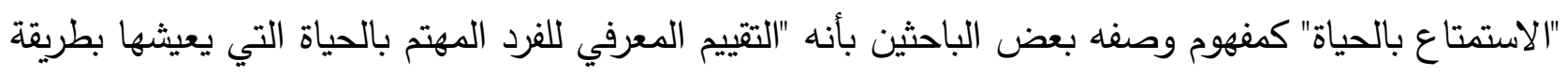

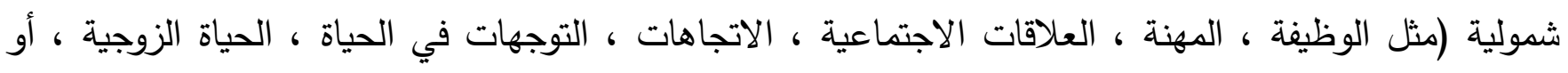
صحته النفسية والجسدية ككل متكامل) (Veenhoven)، 
مجلة أبحاث ميسان ، المجلد السادس عشر، العدد الثاني والثلاثون ، كانون الأول، السنة 2020

2- المكون العاطفي: يشير هذا المكون إلى مجموعة من المشاعر الإيجابية التي تحقق إحساسًا عامًا بالبهجة

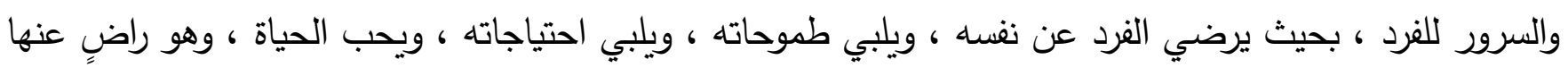

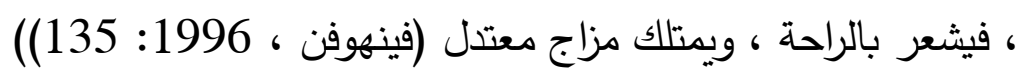

كما يشير إلى كثرة المشاعر الإيجابية أو غياب التأثيرات السلبية هذا ما أسميه الإحساس بالوجود والثعور

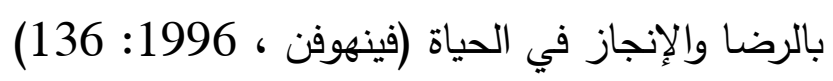

3.المكون الاجتماعي السلوكي يثير هذا المكون إلى قدرة الفرد على ترجمة الإحساس الإيجابي بالاستمتاع بالحياة ,

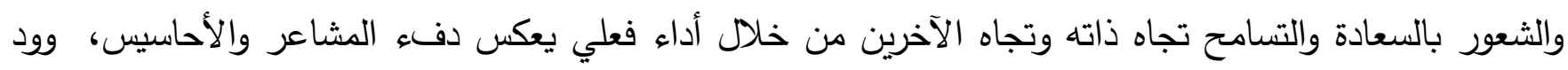

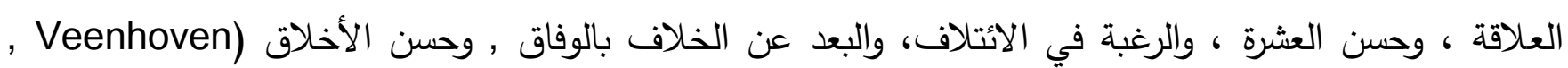
(178: 1996

4.المكون السلوكي الاجتماعي: يشير هذا الدكون إلى قدرة الفرد على ترجمة الثعور الإيجابي بالاستمتاع بالحياة

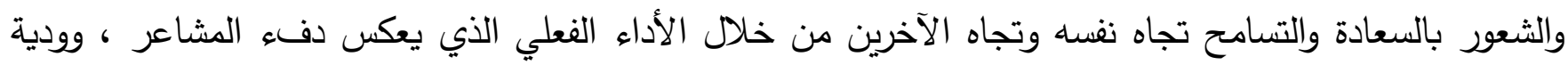

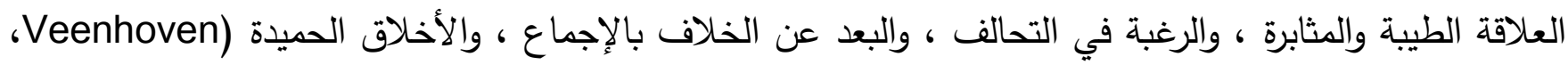
(178:1996

الدراسات السابقة

اولا: الدراسات السابقة الخاصة بالرضا الوظيفي

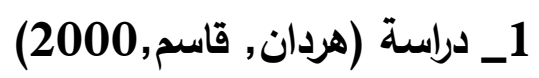

(الرضا الوظيفي لاى معلمات مرحلة رياض الاطفال )

استهدف البحث التعرف على قياس مستوى الرضا الوظيفي لدى معلمات مرحلة رياض الاطفال ومعرفة الفروق الفردية في درجة الرضا الوظيفي وحسب العمر والتحصيل الدراسي ونوع التخصص , وتمثلت عينة البحث (200)

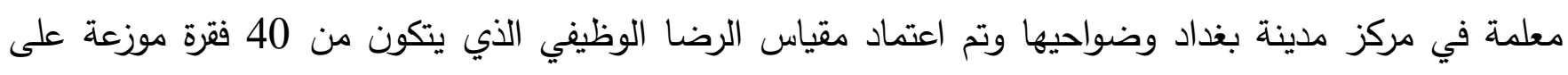

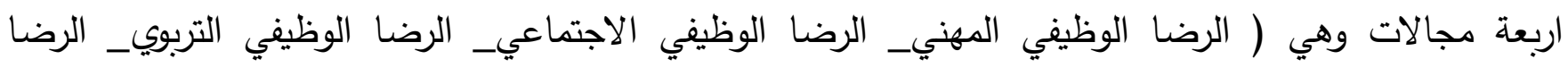


مجلة أبحاث ميسان ، المجلد السادس عشر، العدد الثاني والثلاثون ، كانون الأول، السنة 2020

الوظيفي النفسي) وقد تم عرض فقرات المقياس ومجالاته على عينة البحث بعد اجراء خاصية الصدق والثبات وتم التوصيل الى النتائج ذات الدلالة الاحصائية لمتغيرات العمر والتحصيل الدراسي وعلاقتة بمستوى الرضا الوظيفي لاى معلمات مرحلة رياض الاطفال.

2_دراسة ( فوزي,وحسين,2005): التِّضا الوظيفي لدى أعضاء هيئة التدريس في الجامعات الخاصة والحكومية في الأردن: دراسة مقارنة لأعضاء هيئة التدريس في كليات العات العلوم الإدارية

تهدف الدراسة الحالية إلى مقارنة مدى توافر الرضا الوظيفي لدى أعضاء هيئة التدريس في كليات العلوم

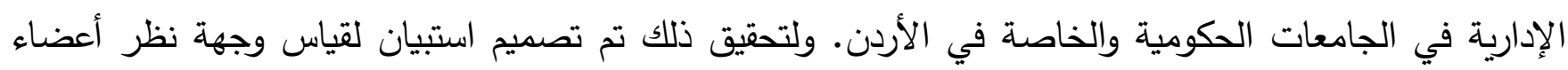
هيئة التدريس تجاه الرضا الوظيفي من خلال العناصر التالية: مكافآت مالية. الإجراءات الإدارية والبحث التاتئ العلمي.

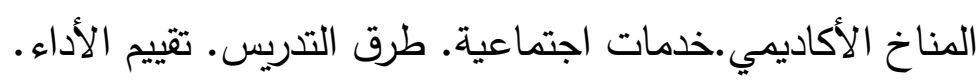

تم استخدام الإحصاء الوصفي لتحليل بيانات العينة ، واستخدم الإحصاء الاستقرائي لاختبار فرضيات الدراسة.

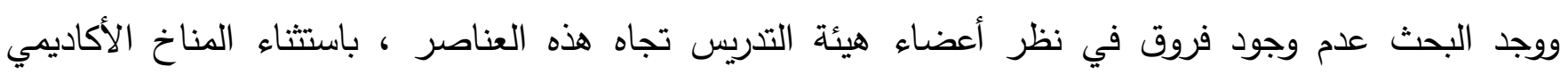
وعناصر تقييم الأداء ، حيث كان رضا أعضاء هيئة التدريس في الجامعات الخاصة أكثر من الجامعات الحكومية. وأوصت الدراسة بضرورة اعتماد أساليب وإجراءات موضوعية ومقبولة في عملية التقييم والتركيز على عملية التتييم

فقط.

ثانيا: الاراسات التي تنـاولت متفير الاستمتاع بالحياة (Judge et al,2005) دراسة

(التقويم الذاتي وعلاقته بكل من الرضا الوظيفي والاستمتاع بالحياة) .

هدفت الدراسة إلى التعرف على العلاقة بين الرضا عن الحياة والرضا الوظيفي والاستمتاع بالحياة حيث تم تطبيق

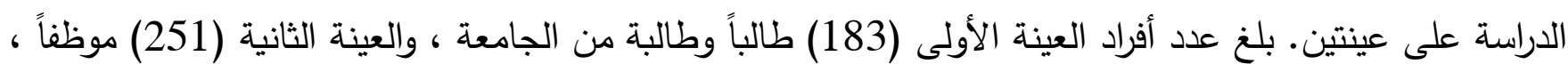

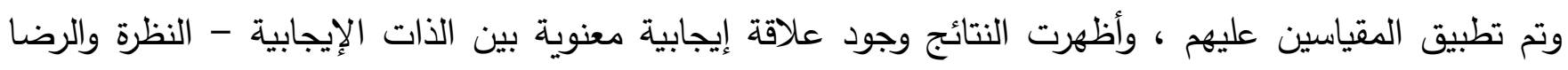
الوظيفي ، وأن الأفراد ذوي النظرة الإيجابية للذات هم أكثر متعة ورضا عن حياتهم (القاضي وآخرون ، 2005: 
مجلة أبحاث ميسان ، المجلد السادس عشر، العدد الثاني والثلاثون ، كانون الأول، السنة 2020

(Steger et al,2008) دراسة

(هل الحياة من دون معنى مرضية ؟ الدور الوسيط للبحث عن معنى للحياة والاستمتاع فيها) .

هدفت الدراسة إلى التعرف على العلاقة بين إيجاد المعنى في الحياة والاستمتاع به حيث تم تطبيق الدراسة على عينة من طلبة الجامعة بلغ عددهم (122).70\% إناث و 83\% من الذكور الأمريكيين ، حيث تم تطبيق كلا المقياسين عليهم ، ووجدت الدراسة علاقة ذات دلالة إحصائية بين معنى الحياة والتمتع بها. خاصة أولئك الأفراد الذين الذين يكافحون لإيجاد معنى لحياتهر

إنهم يعيدون إحيائها ، بينما انخفض هذا الارتباط لاى الأفراد الذين لا يبذلون جهدًا لإيجاد معنى في حياتهم (Steger et al , 2008 :98-100) التعليق على الدراسات السابقة

وظف الباحث الدراسات السابقة في : • بلورة مشكلة البحث واهميته ومصطلحاته

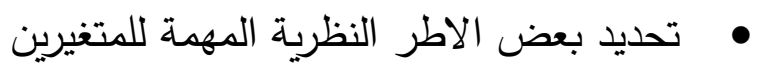

$$
\begin{aligned}
& \text { • اختيار ادوات البحث المناسبة } \\
& \text { • تحديد الوسائل الاحصائية }
\end{aligned}
$$

• معرفة موقع الدراسة الحالية من الدراسات السابقة 
مجلة أبحاث ميسان ، المجلد السادس عشر، العدد الثاني والثلاثون ، كانون الأول، السنة 2020

$$
\text { إجراء الفص الثالث }
$$

مقدمة :

يشمل هذا الفصل على وصف لمنهجية البحث ومجتمعه وعيناته ، وأدوات البحث وخصائصها السيكومترية ، والطرق الإحصائية المستخدمة في إجراءات البحث.

منهجية البحث

ولتحقيق أهداف البحث اعتمد الباحث على المنهج الوصفي حيث يتوافق مع الدراسة الحالية والإجراءات المتبعة فيها ، بالإضافة إلى أن المنهج الوصفي من أكثر الطرق شيوعًا واستخداما.

\section{مجتمع البحث}

يتكون مجتمع البحث الحالي من معلمي المرحلة الابتدائية في محافظة البصرة للعام الدراسي 2019-2020. 
مجلة أبحاث ميسان ، المجلد السادس عشر، العدد الثاني والثلاثون ، كانون الأول، السنة 2020

عينة البحث

ولتحقيق أهداف البحث الحالي استخدم الباحثة أدوات البحث على خطوات متعددة، حيث سيشرح الباحث طريقة اختيار كل عينة وحجمها ووظيفتها كل حسب الإجراء المتبع.

أدوات البحث

أولا: مقياس الرضا الوظيفي

وصف المقياس

تبنى الباحث مقياس الرضا الوظيفي(فوزي وحسين,2005): وهو مقياس معد لقياس الرضا الوظيفي لدى المدرسين

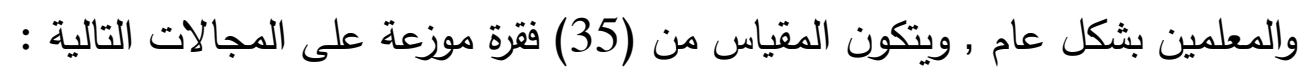

الرضا الوظيفي , المكافآت المالية , المناخ الأكاديمي, التسهيلات ووسائل التدريس , الإجراءات الإدارية والبحث العلمي, خدمات اجتماعية وطبية

التحليل المنطقي للفقرات

عرض الباحث مجالات مقياس (الرضا الوظيفي) على مجموعة من المحكمين الذين بلغ عددهم (15) خبيرا ومحكما في اختصاص الإدارة والقياس والتقويم والارشاد النفسي والتوجيه التربوي ، حيث طلب مني منهم إبداء الرأي في صدق المجالات في شكلها الخارجي ، ومدى لاعمتها لطبيعة الموضوع ، وقد اعتمد الباحث على النسبة المئوية

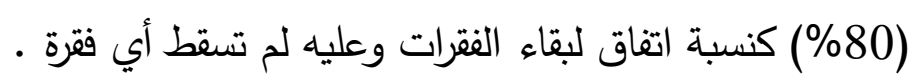

\section{وضوح التعليمات وفهم العبارات}

للتحقق من مدى فهم العينة للمقياس والتعليمات ، وكذلك لمعرفة طريقة الاجابة على كراسة الإجابة المنفصلة ، وللتعرف على متوسط الوقت المطلوب للإجابة على المقياس ، طبق الباحث المقياس على عينة استقصائية قوامها (60) معلما ومعلمة. أظهرت التجربة أن الفقرات واضحة والتعليمات بسيطة ، وقد أظهرت التجربة أن متوسط الوقت المستغرق للرد على الفقرات هو (11) دقيقة. 
مجلة أبحاث ميسان ، المجلد السادس عشر، العدد الثاني والثلاثون ، كانون الأول، السنة 2020

التحليل الإحصائي للفقرات

تعتبر عملية التحليل الإحصائي لأقسام المقياس من الخطوات الأساسية والمهمة ، لأن اعتماد الفقرات ذات

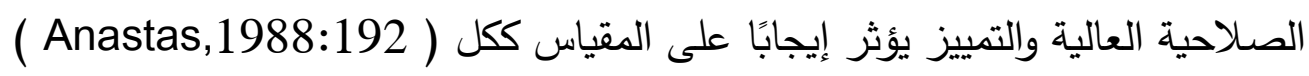
حساب الخصائص السيكومترية للفقرات "يتقق الخبراء في القياس على ضرورة التحقق من صدق الفقرات ومعاملات تمييزها قبل استخدامها" (الزيباري . $75: 1997$,

أ- القوة التمييزية للفقرات

بعد تطبيق المقياس عينة من (200) معلم ومعلمة لاستخراج الصدق التمييزي للمقياس ، ثم قام الباحث بترتيب

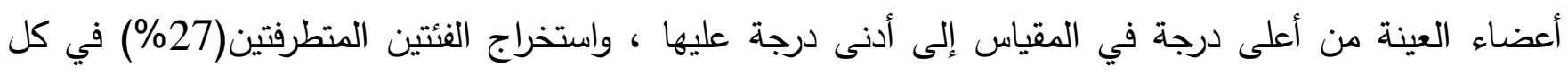

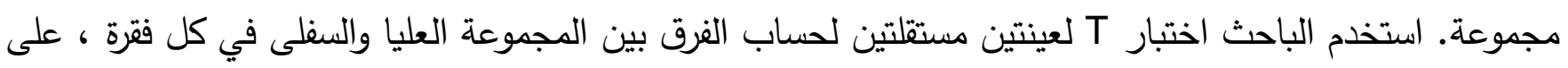

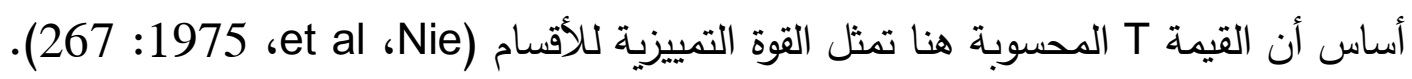
ب- صدق الفقرات

في حساب صدق الفقرة ، اعتمد الباحث على معامل الارتباط (بيرسون) ، بين درجة كل فقرة والنتيجة الإجمالية ، لأن الدرجات مستمرة وتدريجية (Dbois, 1962 : 144)

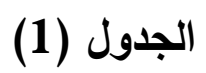

القوة التمييزية لفقرات المقياس ومعاملات صدقها

\begin{tabular}{|c|c|c|c|c|c|}
\hline معامل صدق & 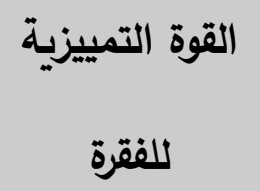 & في المقياس الفقرة & | معامل صدق" & القوة التمييزية & في المقياس الفقرة \\
\hline 0.347 & 6.456 & 19 & 0.321 & 4.567 & 1 \\
\hline
\end{tabular}


مجلة أبحاث ميسان ، المجلد السادس عشر، العدد الثاني والثلاثون ، كانون الأول، السنة 2020

\begin{tabular}{|c|c|c|c|c|c|}
\hline 0.457 & 7.445 & 20 & 0.236 & 5.679 & 2 \\
\hline 0.347 & 5.437 & 21 & 0.346 & 3.459 & 3 \\
\hline 0.457 & 6.348 & 22 & 0.347 & 5.678 & 4 \\
\hline 0.457 & 6.457 & 23 & 0.235 & 4.568 & 5 \\
\hline 0.567 & 6.346 & 24 & 0.247 & 7.654 & 6 \\
\hline 0.457 & 5.548 & 25 & 0.457 & 6.547 & 7 \\
\hline 0.567 & 6.348 & 26 & 0.346 & 8.346 & 8 \\
\hline 0.457 & 7.456 & 27 & 0.347 & 8.235 & 9 \\
\hline 0.458 & 9.347 & 28 & 0.457 & 6.548 & 10 \\
\hline 0.459 & 6.578 & 29 & 0.457 & 7.568 & 11 \\
\hline 0.347 & 7.457 & 30 & 0.346 & 5.679 & 12 \\
\hline 0.457 & 6.457 & 31 & 0.458 & 6.435 & 13 \\
\hline 0.457 & 6.27 & 32 & 0.347 & 6.547 & 14 \\
\hline 0.457 & 7.345 & 33 & 0.543 & 7.658 & 15 \\
\hline 0.457 & 6.543 & 34 & 0.458 & 8.457 & 16 \\
\hline 0.326 & 5.458 & 35 & 0.458 & 6.546 & 17 \\
\hline$* * * * * *$ & $* * * * * *$ & $* * * *$ & 0.457 & 7.546 & 19 \\
\hline
\end{tabular}

ومن خلال الجدول السابق ,نلاحظ تمتع جميع الفقرات بقوة تمييز وصدق جيد . 
مجلة أبحاث ميسان ، المجلد السادس عشر، العدد الثاني والثلاثون ، كانون الأول، السنة 2020 وقد حسب الباحث الثبات بأكثر من طريقة وكما يأتي :

1 - مريقة أعادة التطبيق

تم تطبيق المقياس على (50) معلم ومعلمة بعد (15) يوم تم تطبيق المقياس مرة اخرى واستخدم الباحث معامل ارتباط (بيرسون) بين التطبيقين حيث كان معامل الثبات (0.80) وهو معامل جيد.

Fakronbach 2-2 طريقة

تتميز هذه الطريقة باتساقها وإمكانية الحصول على نتائج موثوقة في حساب العلاقة بين مجموعة فقرات المقياس ،

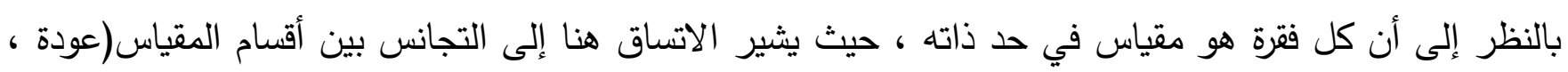
2000: 354) ، و لاستخراج تناسق طريقة فاكرونباخ رحيث طبق الباحث معادلة الفا كرونباخ (0.83).

ثانيا :مقياس الاستمتاع بالحياة

وصف المقياس 
مجلة أبحاث ميسان ، المجلد السادس عشر، العدد الثاني والثلاثون ، كانون الأول، السنة 2020

تبنى الباحث مقياس الاستمتاع بالحياة(ايمان,2020): وهو مقياس معد لقياس الاستمتاع بالحياة بشكل عام ,

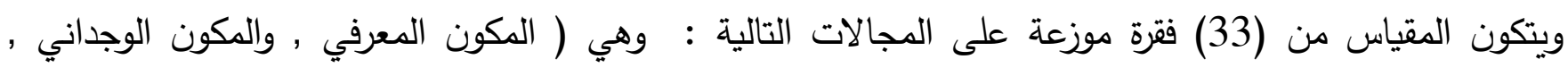
والمكون الاجتماعي السلوكي) التحليل المنطقي للفقرات

عرض الباحث مجالات مقياس (الاستمتاع بالحياة) على مجموعة من المحكمين الذين بلغ عددهم (15) خبيرا

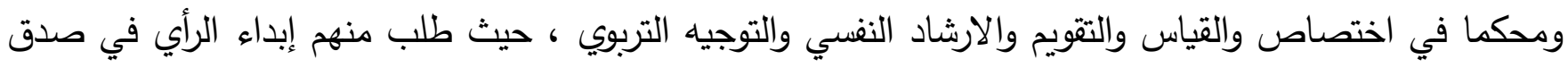
المجالات في شكلها الخارجي ، ومدى لاعمتها لطبيعة الموضوع ، وقد اعتمد الباحث على النسبة المئوية (80\%)

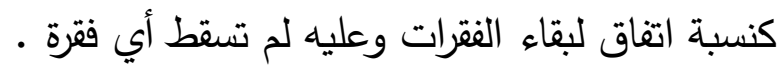

\section{وضوح التعليمات وفهم العبارات}

للتحقق من مدى فهم العينة للمقياس والتعليمات ، وكذلك لمعرفة طريقة الاجابة على كراسة الإجابة المنفصلة ، وللتعرف على متوسط الوقت المطلوب للإجابة على المقياس ، طبق الباحث المقياس على عينة استقصائية قوامها (60) معلما ومعلمة. أظهرت التجربة أن الفقرات واضحة والتعليمات بسيطة ، وقد أظهرت التجربة أن متوسط الوقت المستغرق للرد على الفقرات هو (12) دقيقة. التحليل الإحصائي للفقرات

تعتبر عملية التحليل الإحصائي لأقسام المقياس من الخطوات الأساسية والمهمة ، لأن اعتماد الفقرات ذات

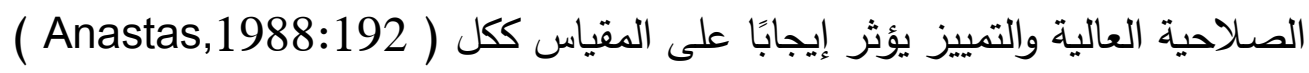
حساب الخصائص السيكومترية للفقرات: "يتقق الخبراء في القياس على ضرورة التحقق من صدق الفقرات ومعاملات تمييزها قبل استخدامها" (الزيباري . $75: 1997$,

أ- القوة التمييزية للفقرات بعد تطبيق المقياس عينة من (200) معلم ومعلمة لاستخراج الصدق التمييزي للمقياس ، ثم قام الباحث بترتيب أعضاء العينة من أعلى درجة في المقياس إلى أدنى درجة عليها ، واستخراج الفئتين المتطرفتين(27\%) في 
كل مجموعة. استخدم الباحث اختبار T لعينتين مستقلتين لحساب الفرق بين المجموعة العليا والسفلى في كل فقرة ،

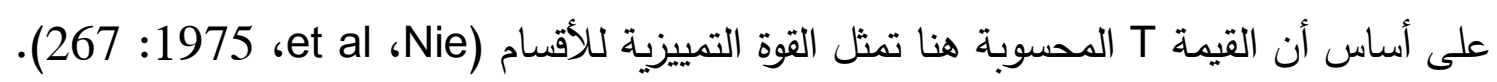
ب- صدق الفقرات

في حساب صدق الفقرة ، اعتمد الباحث على معامل الارتباط (بيرسون) ، بين درجة كل فقرة والنتيجة الإجمالية

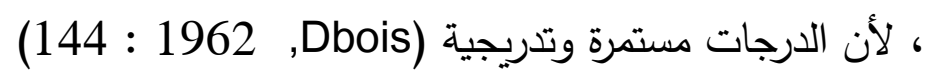

(2) (الجدول)

القوة التمييزية لفقرات المقياس ومعاملات صدقها

\begin{tabular}{|c|c|c|c|c|c|}
\hline معامل صدق الفقرة & القوة التمييزية & رقم الفقرة & "الفقرة & القوة التمييزية" & في المقياس الفقرة \\
\hline 0.457 & 5.435 & 5.445 & 0.543 & 6.457 & 1 \\
\hline 0.346 & 4.321 & 6.457 & 0.345 & 5.458 & 2 \\
\hline 0.543 & 5.321 & 7.456 & 0.346 & 8.347 & 3 \\
\hline 0.346 & 5.347 & 6.345 & 0.346 & 8.753 & 4 \\
\hline 0.321 & 4.321 & 6.346 & 0.342 & 7.568 & 5 \\
\hline 0.432 & 4.213 & 6.345 & 0.435 & 7.457 & 6 \\
\hline
\end{tabular}


مجلة أبحاث ميسان ، المجلد السادس عشر، العدد الثاني والثلاثون ، كانون الأول، السنة 2020

\begin{tabular}{|l|l|l|l|l|c|}
\hline 0.457 & 7.431 & 6.234 & 0.431 & 7.457 & 7 \\
\hline 0.432 & 4.348 & 5.235 & 0.457 & 7.567 & 8 \\
0.346 & 5.432 & 8.346 & 0.453 & 5.456 & 9 \\
\hline 0.431 & 6.543 & 7.346 & 0.431 & 6.456 & 10 \\
\hline 0.347 & 6.468 & 5.346 & 0.457 & 7.347 & 11 \\
\hline 0.543 & 6.542 & 5.346 & 0.567 & 4.568 & 12 \\
\hline 0.458 & 5.312 & 5.345 & 0.543 & 3.467 & 13 \\
\hline 0.321 & 5.321 & 6.345 & 0.457 & 6.345 & 14 \\
\hline 0.431 & 7.432 & 6.346 & 0.432 & 5.457 & 15 \\
\hline 0.457 & 5.321 & 5.324 & 0.456 & 6.321 & 16 \\
\hline 0.456 & 4.327 & 5.477 & 0.456 & 5.568 & 17 \\
\hline
\end{tabular}

ومن خلال الجدول السابق ,نلاحظ تمتع جميع الفقرات بقوة تمييز وصدق جيد .

ثبات المقياس

وقد حسب الباحث الثبات بأكثر من طريقة وكما يأتي :

1 - بريقة أعادة التطبيق

تم تطبيق المقياس على (50) معلم ومعلمة بعد (15) يوم تم تطبيق المقياس مرة اخرى واستخدم الباحث معامل ارتباط (بيرسون) بين التطبيقين حيث كان معامل الثبات (0.81) وهو معامل جيد 
مجلة أبحاث ميسان ، المجلد السادس عشر، العدد الثاني والثلاثون ، كانون الأول، السنة 2020

Fakronbach 2- طريقة

تتميز هذه الطريقة باتساقها وإمكانية الحصول على نتائج موثوقة في حساب العلاقة بين مجموعة فقرات المقياس ، بالنظر إلى أن كل فقرة هو مقياس في حد ذاته ، حيث يثير الاتساق هنا إلى التجانس بين أقسام المقياس(عودة ، 2000: 354) ، و لاستخراج تتاسق طريقة فاكرونباخ ,حيث طبق الباحث معادلة الفا كرونباخ (0.82). الوسائل الإحصائية

أن الوسائل الإحصائية التي استخدمها الباحث في البحث الحالي حسبت بوساطة برنامج الحاسوب الآلي (SPSS) هي

1) معامل ارتباط بيرسون Person Correlation Coefficient : من اجل التعرف على الثبات بطريقة اعادة التطبيق ,ومن اجل ايجاد العلاقة بين المتغيرين

2) الاختبار التائي T-test لعينتين مستقلتين : من اجل حساب القوة التمييزية للفترات . 3)الاختبار التائي لعينة واحدة : للتعرف على مستوى تواجد المتغيرات لدى عينة البحث .

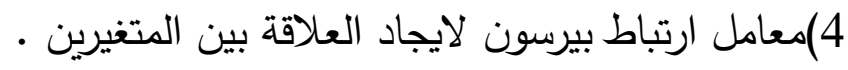


الفصل الرابع

نتائج البحث

يتضمن هذا الفصل عرضا لنتائج البحث التي توصل اليها ,على وفق الاهداف التي تم عرضها في الفصل الاول

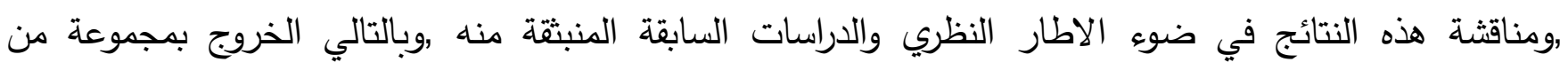
الاستنتاجات والتوصيات والمقترحات

الهذف الاول : التعرف على مستوى الرضا الوظيفي لاى معلمي المرحلة الابتائية في محافظة البصرة لقد بينت النتائج ان المتوسط الحسابي لعينة البحث هي (122.76) بانحراف معياري قدرة (7.606) وعند مقارنة هذا الوسط بالوسط الفرضي للبحث (105) وباستعمال الاختبار التائي لعينة واحدة روجد ان القيمة التئة التائية

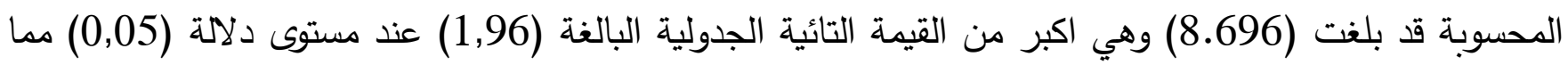

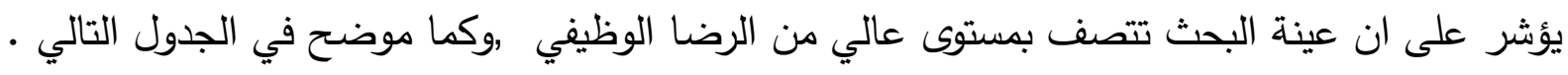

$$
\text { (الجدول (3) }
$$

نتائج الاختبار التائي لعينة واحدة للتعرف على الفرق بين متوسط العينة والمجتمع

\begin{tabular}{|c|c|c|c|c|c|c|}
\hline مستوى & الجيمة الجدولية & القحسيمة $\quad$ التائية & الفرضي المتوسط & الالانحراف & الحستوسط الحسي & علد العراد \\
\hline 0,05 & 1,96 & 8.696 & 105 & 7.606 & 122.76 & 200 \\
\hline
\end{tabular}

حيث تتفق هذه النتيجة مع نتائج الدراسات السابقة, التي اشارت الى وجود مستوى متوسط او جيد من الرضا الوظيفي لدى العاملين • 
الههف الثاني : التعرف على مستوى الاستمتاع بالحياة لاى معلمي المرحلة الابتدائية في محافظة البصرة لقد بينت النتائج ان المتوسط الحسابي لعينة البحث هو (114.56) بانحراف معياري قدرة (3.254) وعند مقارنة هذا الوسط بالوسط الفرضي للبحث (99) وباستعمال الاختبار التائي لعينة واحدة بوجد ان القيمة التائية

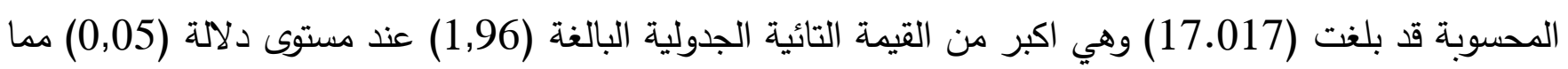

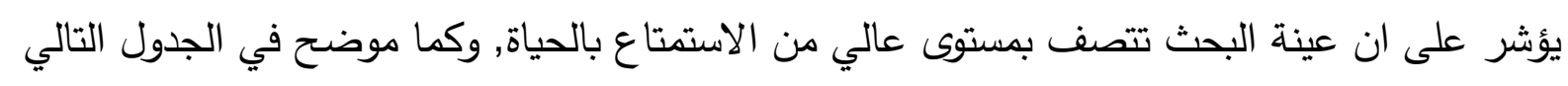

(4) (الجدول) (4) (2) (2)

نتائج الاختبار التائي لعينة واحدة للتعرف على الفرق بين متوسط العينة والمجتمع

\begin{tabular}{|c|c|c|c|c|c|c|}
\hline مستوى & الجيمة & القيمة & الفرضي المتوسط & الانحراف & الحسابي & العينة افراد \\
\hline 0,05 & 1,96 & 17.017 & 99 & 3.254 & 114.56 & 200 \\
\hline
\end{tabular}

حيث تتقق هذه الدراسة مع الدراسات السابقة التي اشارت الى وجود مستوى من الاستمتاع بالحياة لدى العاملين في

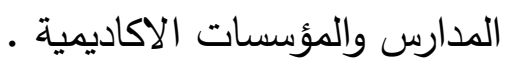

الهذف السابع: التعرف على العلاقة ذات الدلالة الاحصائية بين الالتزام التظظيمي والاداء الوظيفي لدى الموظفين 
مجلة أبحاث ميسان ، المجلد السادس عشر، العدد الثاني والثلاثون ، كانون الأول، السنة 2020

ويتضح من خلال قيمة معامل ارتباط بيرسون ان هنالك علاقة طرية موجبة بين المتغيرين ,وهذا يؤشر ان زيادة

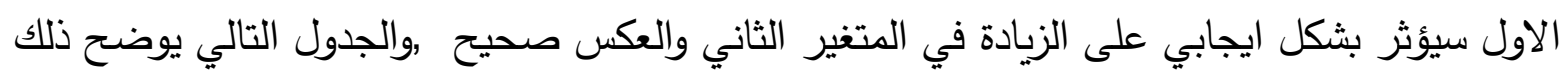

(5) (5دول)

قيمة معامل ارتباط بيرسون بين الرضا الوظيفي والاستمتاع بالحياة

\begin{tabular}{|c|c|c|}
\hline قيمة معامل الارتباط العتغينة & \\
\hline 0,76 & 200 & الاستمتاع بالحياة \\
\hline
\end{tabular}

وتتقق هذه النتيجة مع دراسة (Judge et al,2005) التي اشارت الى وجود علاقة ارتباطية موجبة الرضا الوظيفي والاستمتاع بالحياة و ركما اشار الاطار النظري التى حقيقة هذه العلاقة . ويرى الباحث ان وجود علاقة ما بين الالتزام التنظيمي والاداء الوظيفي امر متوقع وطبيعي لدى عينة البحث ,فمن

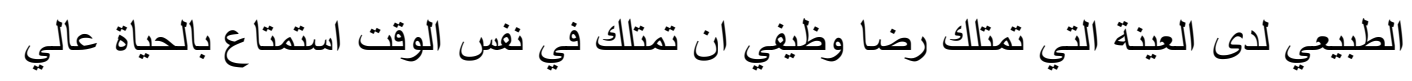

الاستنتاجات

• هنالك مستوى عالي من الرضا الوظيفي لدى معلمي المرحلة الابتدائية في محافظة البصرة

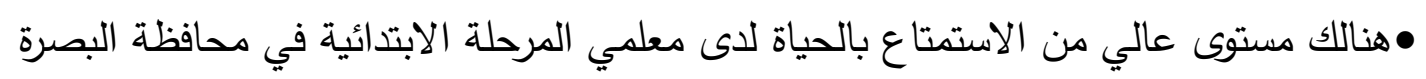
• هنالك علاقة ذات دلالة احصائية بين الرضا الوظيفي والاستمتاع بالحياة لاعى معلمي المرحلة الابتدائية في لئي محافظة البصرة . n مهاع 
مجلة أبحاث ميسان ، المجلد السادس عشر، العدد الثاني والثلاثون ، كانون الأول، السنة 2020

التوصيات

ضرورة تسليط الضوء على الرضا الوظيفي في المؤسسات واقامة ورشات عمل تدريبية حول اهميته في تطوير

$$
\text { المدارس }
$$

العمل على ارسال بعثات من المعلمين الى خارج البلد ,للتعرف على اخر المستجدات في مجال العمل التدريسي

$$
\text { واستراتيجيات التدريس الحديثة . }
$$

ضرورة العمل على تحسين المناخ الوظيفي للمعلمين بما يساهم في رفع مستوى الاستمتاع بالحياة

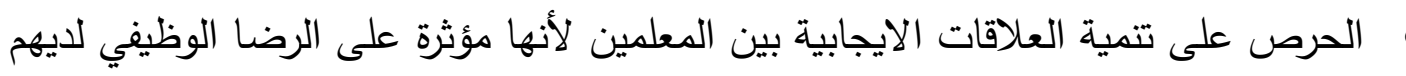

ضرورة تحفيز المعلمين ماديا ومعنويا

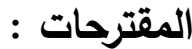

استكمالا للبحث الحالي يقترح الباحث العناوين التالية :

الرضا الوظيفي وعلاقته بالالتزام التتظيمي لدى موظفي مطار بغداد

العدالة التظظيمية وبقوة الارادة لدى مدراء الاقسام في الكليات العراقية

التمكين النفسي وعلاقته بالاداء الوظيفي لاى موظفي وزارة العمل والثؤن الاجتماعية .

الرشوي , محمد عبد الله , ( 1997 ) مفهوم الذات وعلاقته بالرضا الوظيفي بالاجهز الامنية , رسالة

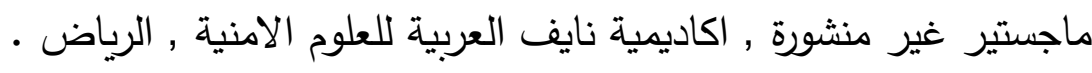

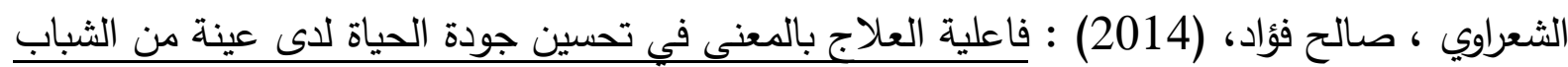

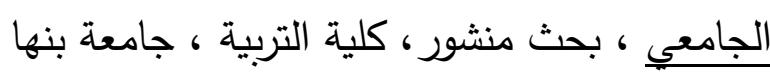
العديلي , محمد حسن(1985): دوافع العاملين في الأجهزة الحكومية في المملكة العربية. الرياض: معهد

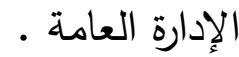

فوزي عبد الله العكش, وحسين احمد مصفى,(2005) : الرّضِا الوظيفي لدى أعضاء هيئة التدريس في

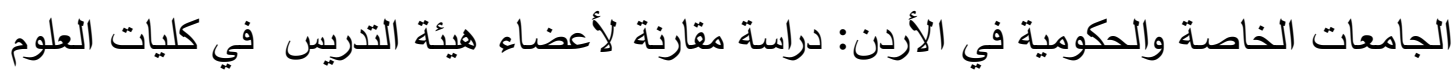
2 الإدارية,مجلة جامعة البترا,العدد 2 
مجلة أبحاث ميسان ، المجلد السادس عشر، العدد الثاني والثلاثون ، كانون الأول، السنة 2020

القبسي, هناء محمد(1996): مستوى الرضا الوظيفي وعلاقة ببعض الخصائص الذاتية والوظيفية لمديرة

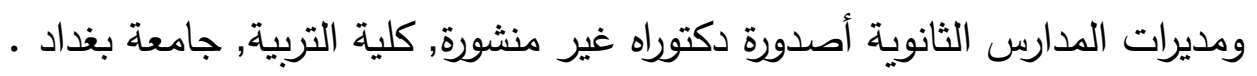
المشعان مؤيد (2003هـ) مصادر الضغوط النفسية لدى الموظفين الإداريين في محافظة اليرموك, مجلد مركز البحوث التربوية, في جامعة قطر , السنة الثامنة. هردان ,قاسم محمد (2000): الرضا الوظيفي لاى معلمات مرحلة رياض الاطفال ,مجلة ابحاث ديالى , العدد فئه التاسع عشر , المجلد الخامس لسنه 2000

-1Veenhoven, R \& .Bunting, B. (1996. A comparative Study of Satisfaction with Life. Europe Eotvo University Predd.

- Reade, R ( 2005 ) : Maintaining Enjoyment of life in the process of liring with high cholesterol : Agrounged theory Rtydy, journal of Personality and Racial psychology, Vol.29, N0.1, new gersey.

- Anastasi A ;(1976): Psychology Testing , N.Y. $4^{\text {Th }}$ Edition Macmillan Co .

- Timothy, A; Judge, J., bono, A., Erez; E.,(2005). Core Self- Evalua-tion and Job and Life Satisfaction- the Role of Self. Concordance and Goal Attainment. Journal of applied Psycholoy

- Veenhoven, R. \& Bunting, B. (1996). A comparative Study of Satisfaction with Life. Europe Eotvo University Press

$$
\text { ملحق(1) اسماء السادة الخبراء }
$$

أسماء الخبراء مرتبة بحسب الألقاب العلمية والحروف الهجائية

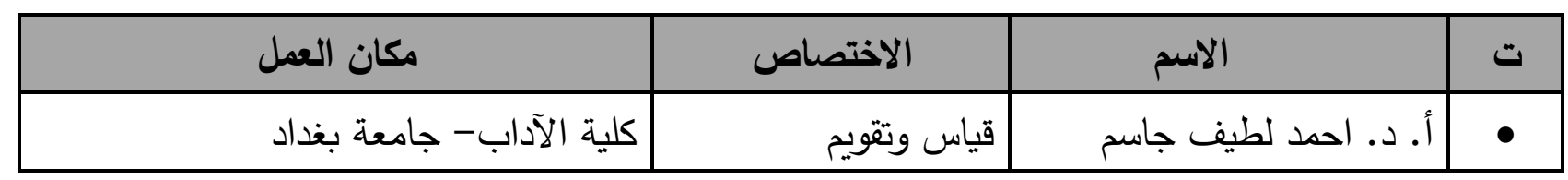


مجلة أبحاث ميسان ، المجلد السادس عشر، العدد الثاني والثلاثون ، كانون الأول، السنة 2020

\begin{tabular}{|c|c|c|c|}
\hline كلية التربية للبنات- جامعة بغداد & علم النفس & | أ. د. الطاف ياسين خضير & $\bullet$ \\
\hline كلية التربية الأساسية-الجامعة المستتصرية & علم النفس التربوي & |أ. د. إيمان عباس الخفاف & $\bullet$ \\
\hline كلية التربية الأساسية-الجامعة المستتصرية & علم النفس التربوي & أ. د. بشرى حسين علي & $\bullet$ \\
\hline كلية التربية الأساسية جامعة ديالى & علم نفس النمو & |أ. د. زهرة موسى جعفر & $\bullet$ \\
\hline كلية التربية الأساسية-الجامعة المستتصرية & علم النفس التربوي & | أ. د. سعدي جاسم عطية & $\bullet$ \\
\hline كلية تربية بنات جامعة بغداد & علم نفس النمو & كاظة & $\bullet$ \\
\hline كلية الآداب- جامعة بغداد & علم النفس الاجتماعي & |أ. د. سناء عيسى محمد & $\bullet$ \\
\hline كلية الآداب- جامعة بغداد & علم النفس العام & |أ. د. سناء مجول فيصل & $\bullet$ \\
\hline كلية التربية بنات - جامعة بغداد & رياض الأطفال & |أ. د. ضحى عادل محمود & • \\
\hline كلية التربية- الجامعة المستتصرية & قياس وتقويم & أ. د.. علي عبد اللطيف & • \\
\hline كلية الآداب- جامعة بغداد & علم النفس الاجتماعي & أ. د. هيثم ضياء عبد الأمير & $\bullet$ \\
\hline كلية الآداب- جامعة بغداد & علم نفس النمو & | أ. م. د. .أروة محمد ربيع & $\bullet$ \\
\hline كلية التربية الأساسية -جامعة ديالى & علم النفس التربوي & | أ. م. د. أياد هاشم محمد & • \\
\hline كلية التربية الأساسية-الجامعة المستتصرية & قياس وتقويم & |أ. م. د. حيدر جليل عباس & $\bullet$ \\
\hline
\end{tabular}

ملحق (2) : مقياس الرضا الوظيفي

\begin{tabular}{|c|c|c|c|c|c|c|}
\hline الرقم & الفقرة & أوبشدة & أوافق & | متوسطة & أوافق & |بشد \\
\hline $\begin{array}{l}1 . \\
.2 \\
.3\end{array}$ & 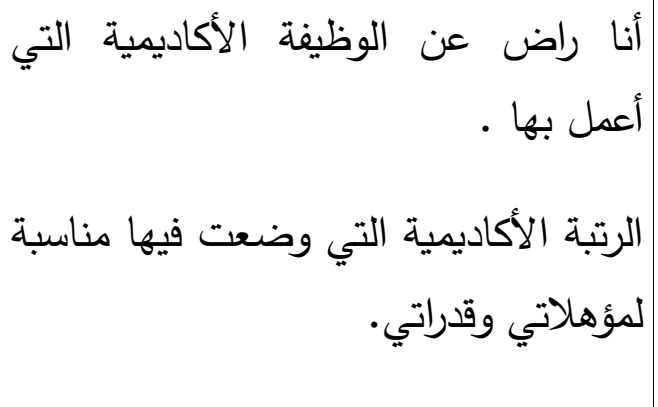 & & & & & \\
\hline
\end{tabular}


مجلة أبحاث ميسان ، المجلد السادس عشر، العدد الثاني والثلاثون ، كانون الأول، السنة 2020

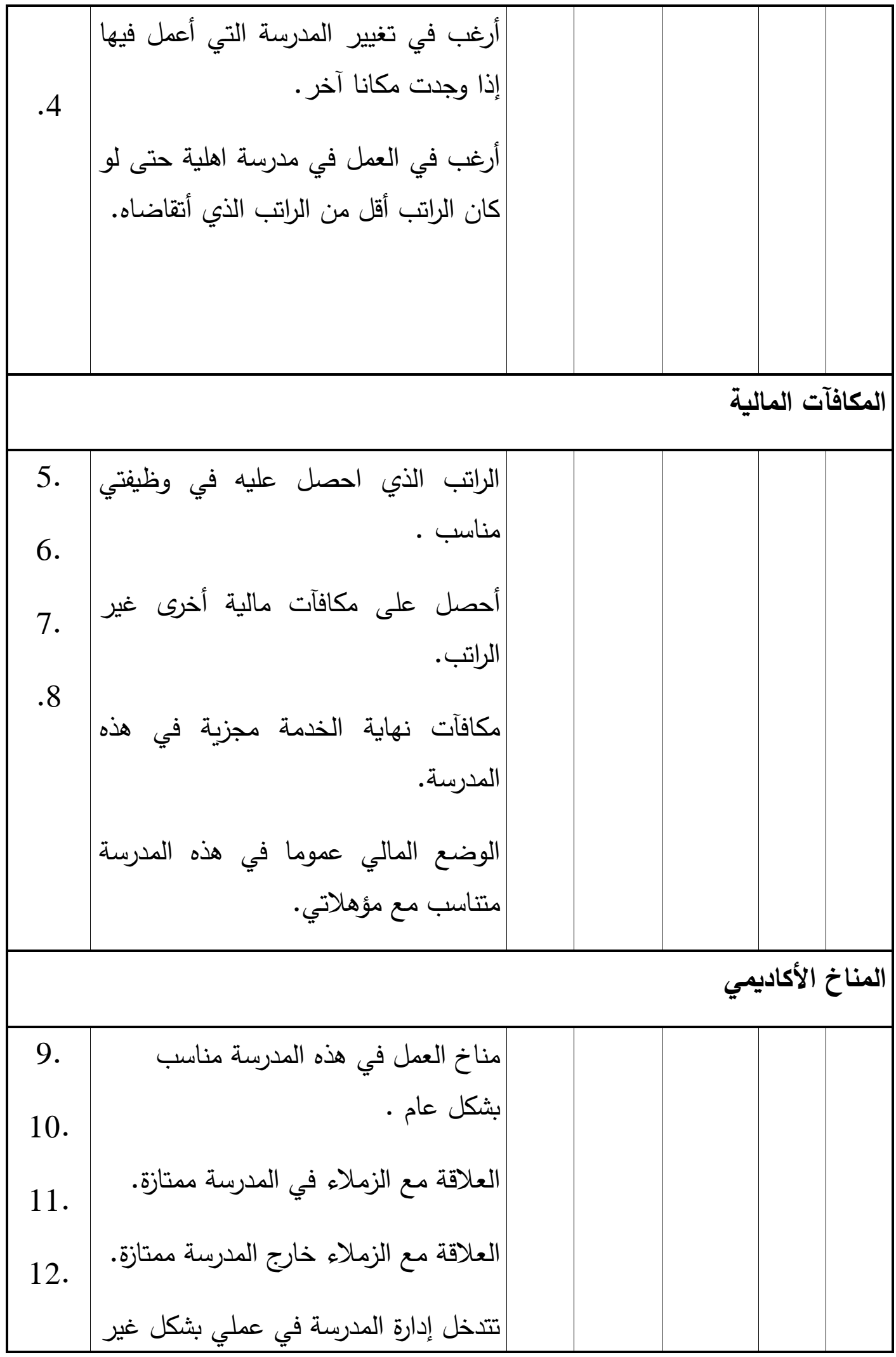


مجلة أبحاث ميسان ، المجلد السادس عشر، العدد الثاني والثلاثون ، كانون الأول، السنة 2020

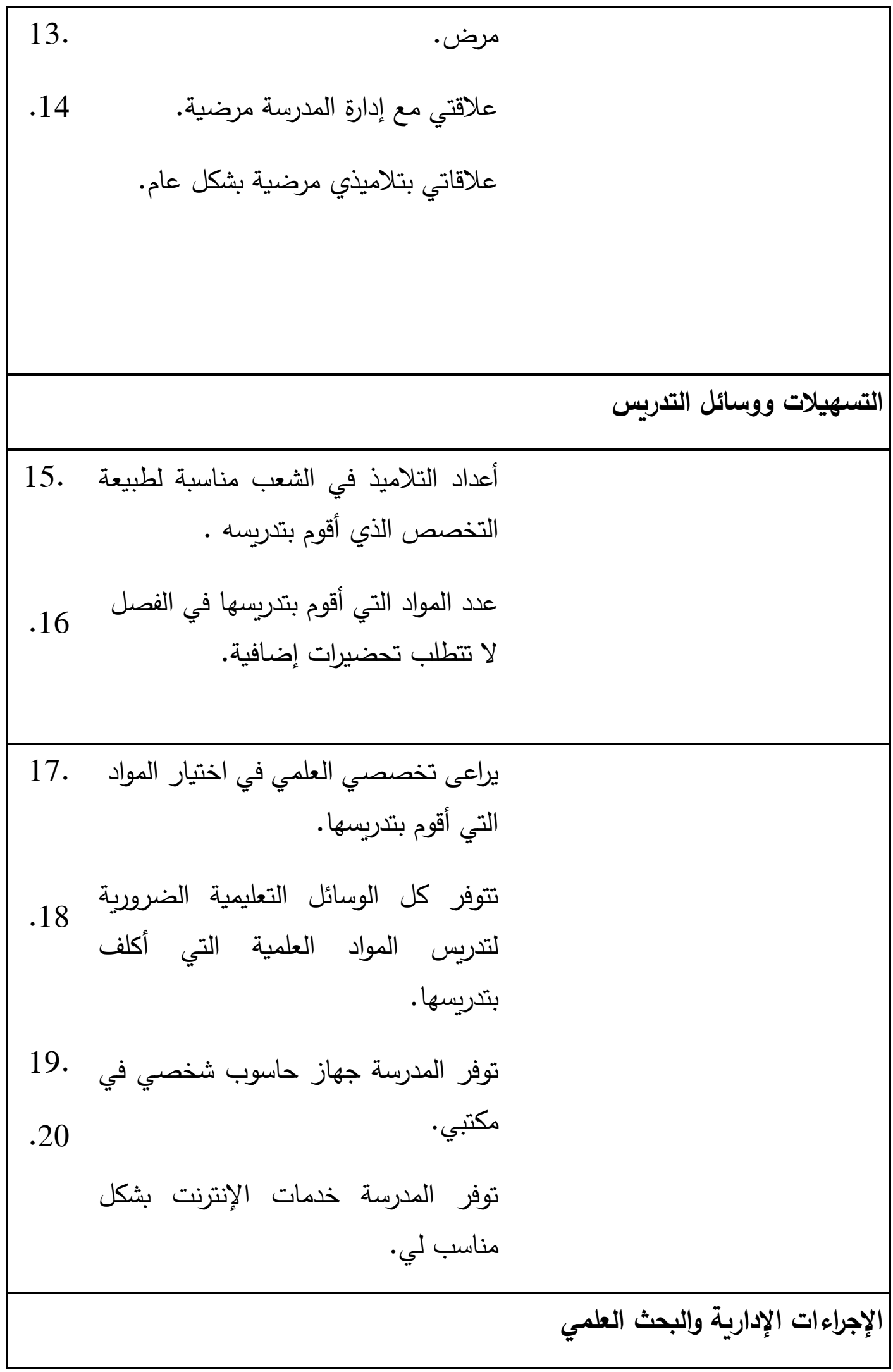


مجلة أبحاث ميسان ، المجلد السادس عشر، العدد الثاني والثلاثون ، كانون الأول، السنة 2020

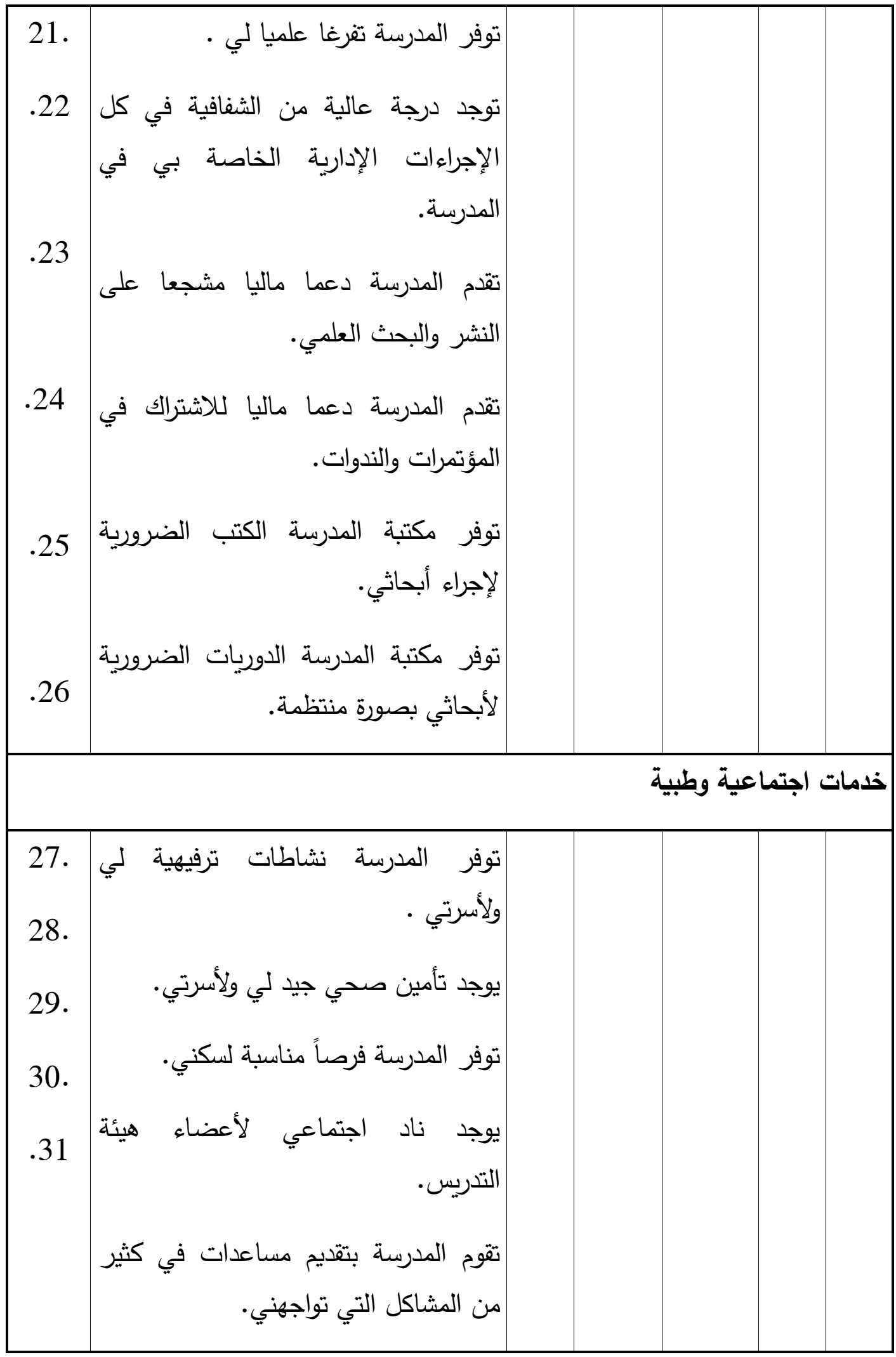


مجلة أبحاث ميسان ، المجلد السادس عشر، العدد الثاني والثلاثون ، كانون الأول، السنة 2020

\begin{tabular}{|c|c|c|}
\hline \multicolumn{3}{|r|}{ تقييم الأداء } \\
\hline $\begin{array}{l}32 \\
33 \\
34 \\
.35\end{array}$ & تيكون & \\
\hline
\end{tabular}

ملحق(3): مقياس الاستمتاع بالحياة

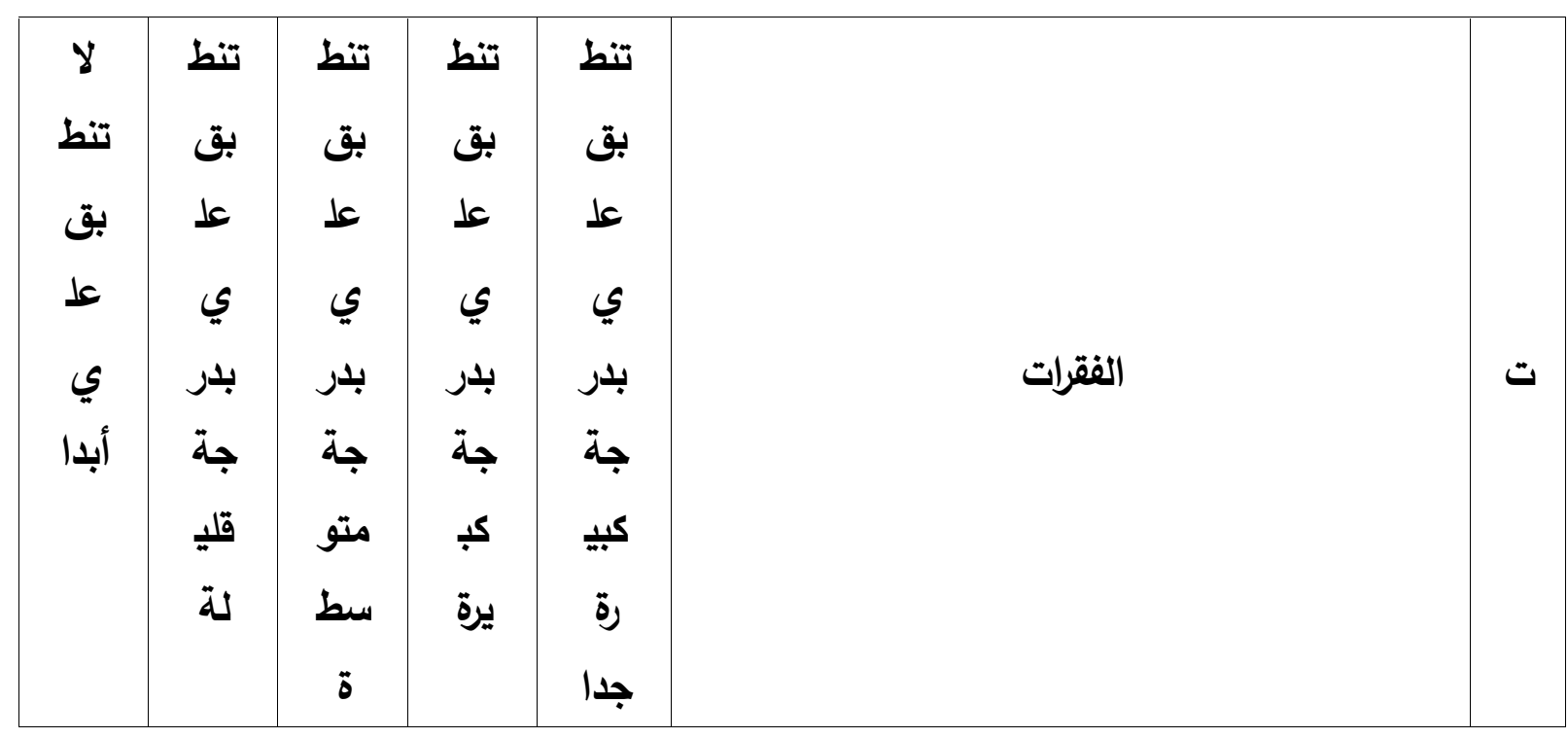


مجلة أبحاث ميسان ، المجلد السادس عشر، العدد الثاني والثلاثون ، كانون الأول، السنة 2020

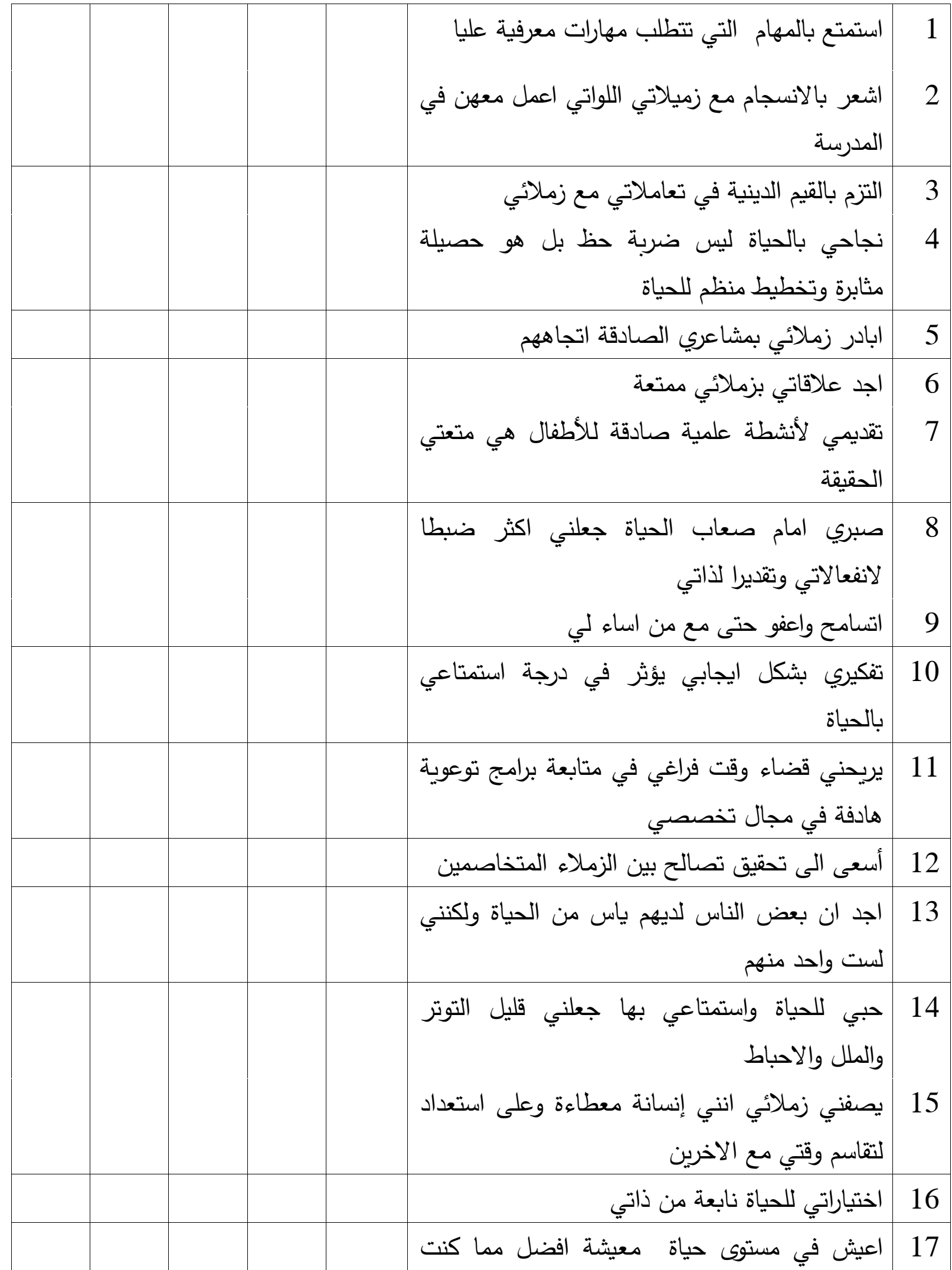


مجلة أبحاث ميسان ، المجلد السادس عشر، العدد الثاني والثلاثون ، كانون الأول، السنة 2020

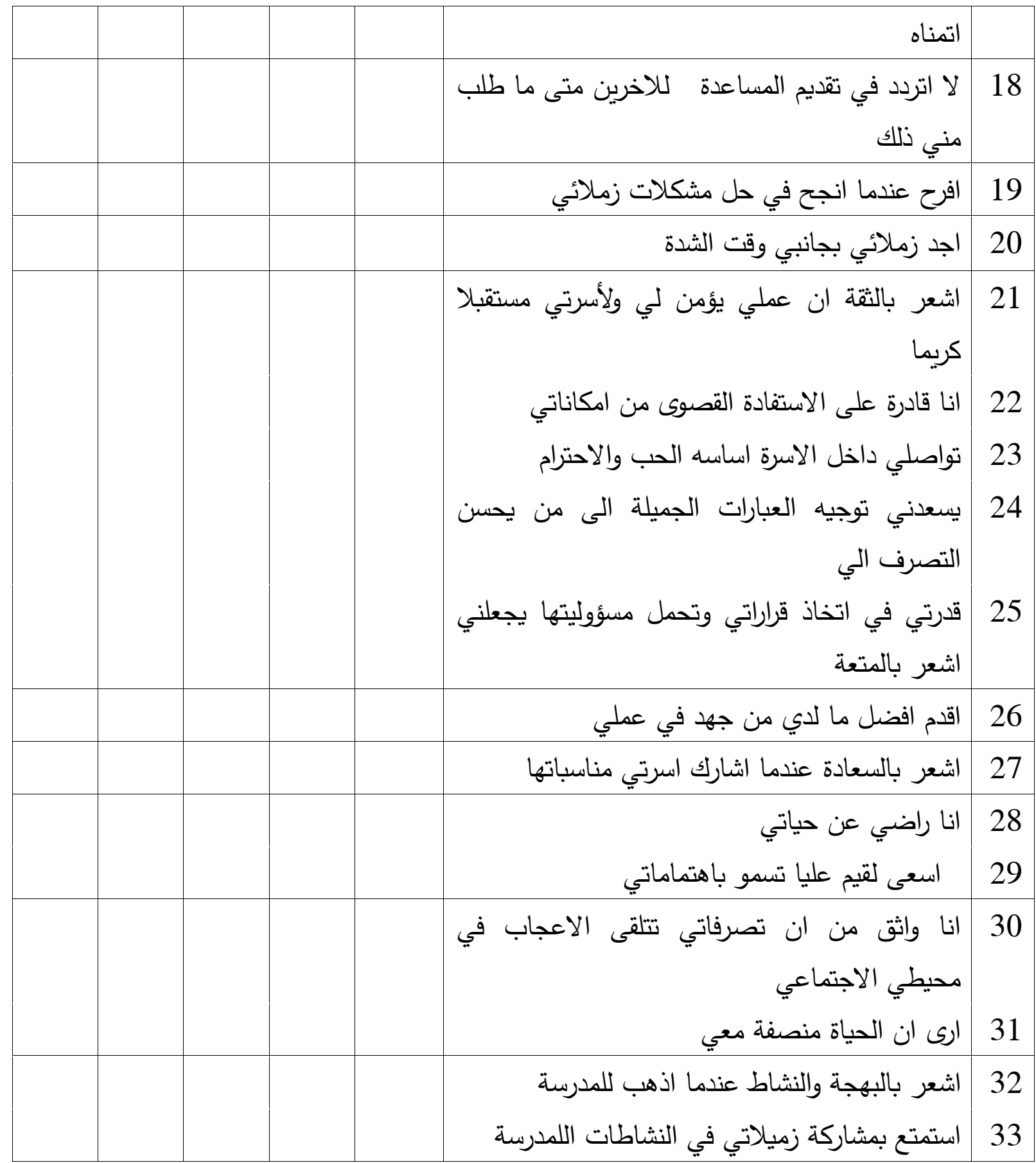

